\title{
O fascínio dos cientistas colombianos pela engenharia genética de plantas
}

QHRISTINA HOMES

\section{Introdução}

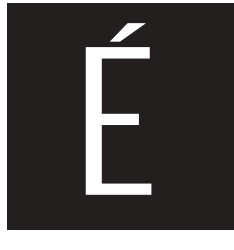

importante entender a perspectiva dos pesquisad ores que trabalham com engenharia genética em um contexto tropical, fora da América do Norte, em função das declarações que têm sido feitas a respeito dessa tecnologia. U ma das principais justificativas oferecidas para a engenharia genética é o seu potencial de contribuir para a agricultura no mundo em desenvolvimento, uma posição que foi proposta, dentre outros, pelo engenheiro agrônomo Norman Borlaug (2001), vencedor do Prêmio Nobel (M cGloughlin, 2002) .

\footnotetext{
* Department of Bioethics. Dalhousie University - cpholmes@ dal.ca

1 Traduzido do original em inglês por M arcelo Severo e revisado por Ivan da Costa M arques. Esta pesquisa foi financiada pela Social Science and Humanities Research Council of Canada (Conselho de Pesquisa em Ciências Sociais e Humanas do Canadá), pelo Canadian Institute of Health Research (Instituto Canadense de Pesquisa em Saúde), e pelo International Development Research Council (Conselho de Pesquisas para o Desenvolvimento Internacional), do Canadá. 0 autor agradece à Technoscience and Regulation Research Unit(U nidade de Pesquisa em Tecnociência e Regulamentação) da U niversidade Dalhousie, Fiona M cD onald, e Russell W yeth, pelo seu apoio e contribuições para este trabalho, assim como todos aqueles que contribuíram com comentários para versões anteriores deste artigo no congresso de 2007 da Associação de Estudos Latino-Americanos (LASA) e nos encontros da Society for Social Studies of Science (4S) em 2007. O s editores deste número especial de SO CIO LO GIAS agradecem a colaboração de O lga Restrepo Forero na revisão das citações mantidas no original em espanhol.
} 
Apesar dessas promessas para o mundo em desenvolvimento, as empresas norte-americanas têm sido fundamentais para o desenvolvimento e a aplicação da engenharia genética de plantas (Lurquin, 2001), com a maior parte das pesquisas que fazem uso desta tecnologia enfatizando 0 hemisfério norte. Dessa forma, muitos países, principalmente nos trópicos, não serão diretamente beneficiados pela tecnologia de engenharia genética, uma vez que esta é atualmente desenvolvida por empresas privadas. Essa prática propicia um conflito interessante entre a maioria das pesquisas que trabalha com essa tecnologia e as justificativas apresentadas para a mesma. Este trabalho discute essa questão através de uma pesquisa realizada na Colômbia, com cientistas envolvid os com pesquisas em engenharia genética.

Foi realizada uma pesquisa etnográfica que inclui observação participante e entrevistas qualitativas com cientistas que fazem uso da engenharia genética na Colômbia, principalmente em contextos públicos, durante um período de oito meses, entre 2004 e 2005. A pesquisa faz parte de um estudo etnográfico mais amplo, em muitos campose acompanha a pesquisa de engenharia genética no Canadá e na Colômbia. 0 projeto como um todo pretende compreender a forma como a tecnologia de engenharia genética é vista por aqueles que a utilizam.

Com base na pesquisa etnográfica realizada na Colômbia, este trabaIho afirma que os cientistas colombianos envolvidos com a biotecnologia têm esperança de diminuir a lacuna entre norte e sul no que diz respeito à importância dessa tecnologia para aprimorar a agricultura em seu país, através do uso da engenharia genética e de outras biotecnologias. 0 artigo primeiro apresenta o contexto global no qual a engenharia genética se tem desenvolvido, inclusive a ênfase da pesquisa em países do hemisfério norte e em projetos lucrativos. Depois, a autora comenta as declarações dos cientistas colombianos sobre o motivo de ver a engenharia genética como sendo útil, que obstáculos eles vêem ao seu trabalho e, por último, por que 
acreditam que é válido prosseguir com suas pesquisas, apesar das dificuldades encontradas.

\section{Biotecnologia de plantas e o predomínio do hemisfério norte}

Antes de discutir os méritos da biotecnologia e da engenharia genética, é preciso ver para onde e para que fins essa tecnologia vem sendo predominantemente destinada. A biotecnologia de plantas é um campo dominado por empresas multinacionais com base nos Estados U nidos, seguidas de perto pelas multinacionais européias. A maioria dos originais e dos principais direitos de propriedade intelectual nesse domínio é detida por empresas com base no hemisfério norte (E.U. ou U.E.) ou então por universidades públicas (Parayil, 2003; Falcon \& Fowler, 2002; Yamin, 2003). Além disso, a pesquisa em biotecnologia de plantas tem enfatizado principalmente culturas mais bem adaptadas ao clima temperado. Por exemplo, quase toda a área atualmente plantada com culturas geneticamente modificadas é composta por quatro culturas: soja (62\%), milho (22\%), algodão (11\%), e colza (5\%) (Brookes \& Barfoot, 2006). Essas quatro culturas são muito importantes para a agricultura norte-americana, que tem a maior área plantada das mesmas, embora essas culturas geneticamente modificadas estejam sendo cada vez mais adotadas no Brasil (soja) e na Índia (algodão) (Brookes \& Barfoot, 2006).

Herrera - Estrella (2000) comparou a situação da biotecnologia agrícola com a da pesquisa médica, nas quais as considerações de mercado têm sido mais importantes do que as idéias filantrópicas e, assim sendo, as doenças tropicais recebem pouca atenção em comparação com as que afetam a América do N orte e a Europa. Da mesma forma, a maior parte das culturas trabalhadas até o momento foi destinada às grandes fazendas mecanizadas que praticam agricultura industrial, e as características foram es- 
colhidas por seu valor econômico. Em função da concentração da biotecnologia agrícola nas mãos de corporações, há pouca probabilidade de que os mecanismos de mercado venham a transferir esta tecnologia para os pequenos agricultores, principalmente aqueles que vivem em países tropicais que não dispõem de recursos suficientes para serem considerados um mercado viável.

Novas plantas e culturas estão sendo desenvolvidasnão para solucionar os problemas da fome e da miséria, mas sim para aumentar o valor das ações das empresas que mais têm investido nos esforços de pesquisa e desenvolvimento no setor da biotecnologia. Aspreferências do consumidor são mais importantes do que os direitos e interesses do agricultor no desenvolvimento e difusão da tecnologia genética agrícola, e a tendência é desenvolver a tecnologia adequada para os interesses das grandes empresas de biotecnologia. (Parayil, 2003: 983).

O contexto no qual se situa a biotecnologia, portanto, consiste na concentração na apropriação de direitos de propriedade intelectual e pesquisa voltada para o mercado, o que parece incompatível com a difusão mundial dessa tecnologia em grande escala. $\mathrm{Na}$ América do N orte, pode-se considerar que este trabalho contribui para a economia e o potencial de exportação, tanto de produtos, quanto de propriedade intelectual. Como esta tecnologia é percebida em um país como a Colômbia?

\section{Biotecnologia de plantas e engenharia genética como uma nova fronteira para os cientistas colombianos}

A participação na 'economia global do conhecimento' (D rucker, 2003) foi de interesse estratégico para muitos governos nacionais (para um exemplo canadense ver M artin, 2001), e a biotecnologia constitui um possível caminho para se alcançar esta meta. 0 potencial para lucrar com seus re- 
cursos genéticos através da biotecnologia também é de interesse para os países da América Latina. Tambornini (2003), por exemplo, defende que a biotecnologia é um caminho para o desenvolvimento e o progresso econômico da América Latina. Este tipo de interesse motivou empreendimentos de bioprospecção, tais como os que foram registrados no M éxico por H ayden (2003). 0 potencial para o desenvolvimento é de particular interesse para a Colômbia, em função da grande biodiversidade encontrada naquele país.

Há um discurso geral de promessa e esperança em torno da biotecnologia como um método para o desenvolvimento da Colômbia. O s membros entrevistados da Colciencias, o maior órgão de financiamento científico da Colômbia, comentaram que a biotecnologia (tanto no campo da saúde quanto no da agricultura) é uma área da ciência na qual eles pretendem tornar a Colômbia internacionalmente competitiva. 0 presidente de uma grande universidade colombiana, ao abrir o congresso de Biotecnologia de Bogotá de 2003, sugeriu que a biotecnologia é um método em potencial para confrontar os problemas do país. Sendo assim, os cientistas colombianos que fazem uso da engenharia genética trabalham imersos no entusiasmo pela biotecnologia, devido às possibilidades que ela oferece como fator de impulso para a economia e, por conseguinte, como mecanismo para alcançar o desenvolvimento social. Esse entusiasmo se reflete na forma como alguns cientistas discutem seu trabalho:

Q ue estas técnicas tienen una importancia estratégica para el desarrollo de países como Colombia, puesto que nosotros somos países mega diversos. Y la ingeniería genética lo que hace es darle valor a todos los recursos genéticos. Como esposible capturar genes en cualquier contexto biológico y desarrollar procesos biotecnológicos con ellos, el resultado es que le da valor a todos los recursos genéticos ya no importa a donde estemos. En ese sentido entonces considero que es una aproximación estratégica la que hago. 


\section{Engenharia genética como instrumento para os cientistas colombianos}

Enquanto o entusiasmo pela biotecnologia esteve presente, muitos dos cientistas colombianos entrevistados para este trabalho salientaram o quanto a engenharia genética é útil como instrumento para alcançar metas particulares, ao invés de fazerem declarações abrangentes so bre a tecnologia. Eles mencionaram várias razões pelasquaisacreditam que a tecnologia seja útil. Em primeiro lugar, porque a engenharia genética proporciona a capacidade de fazer coisas que outros métodosnão poderiam. U m pesquisador, por exemplo, discutiu a capacidade de saber exatamente qual característica foi adicionada à planta e de garantir que esta característica permaneça na nova variedade:

Con transformación genética hay un abanico de posibilidades. Es quizásla única herramienta para obtener variedadesmejoradas eficientes porque cuando se hace mejoramiento genético por simple selección, con el tiempo esa característica se va perdiendo. En cambio, con estos procesos es más estable.

A engenharia genética também foi considerada proveitosa e permitia a utilização de genes que até então não estavam disponíveis em plantas que fossem relacionadas (afastando, assim, a possibilidade de melhoramento convencional). O utro pesquisador, por exemplo, fala de usar esta técnica para resolver um problema do cafeeiro que não pode ser superado pelos métodos convencionais:

El problema es que con la plaga que noso tros trabajamos en particular, que es la broca del café, no se ha encontrado hasta el momento ningún material que sea resistente, entonces es muy difícil pensar en un método tradicional. Sin embargo, hay muchas investigaciones; el centro de investigación está haciendo investigación en esta área para versi de pronto se pueden hacercruzamientos 
genéticos convencionaleso(?) algún mejoramiento, pero aún no se ha logrado, de ahí que hayaamos tenido que recurrir a la investigación en métodos que no sean tradicionales para producir lo mismo, una planta que se pueda defender mejor contra la broca del café. ¿Cómo veo la biotecnología? La veo como una herramienta que nos ayuda a producir una planta resistente a la plaga, que es nuestro problema, y que le pueda ayudar a los agricultores.

A engenharia genética é vista também como um método que permitirá aos agricultores colombianos alcançarem resultados importantes mais rapidamente do que obteriam com os métodos convencionais. Este o caso específico das culturas que são difíceis de trabalhar, mas importantes para a alimentação colombiana, tais como a mandioca e, neste caso em particular, a banana-da-terra:

El plátano híbrido es difícil de mejorar yeste proceso puede tomar 40 años. Esta es una estrategia de 10 ó 15 años pero si se compara con un fitomejoramiento tradicional, es mucho lo que se ahorra. Y también que esa variedad pueda ser usada por pequeños productoresporque el plátano no le importa a las multinacionales y es un producto de productor pequeño. A lo que se están enfocando entonceses a que lospequeñosproductorestengan acceso a la biotecnología y a variedadesobtenidas por ellos.

A engenharia genética surgiu como uma excitante possibilidade de melhoria para as culturas tropicais, e não para as culturas temperadas que as multinacionais já estavam desenvolvendo. As culturas tropicais foram negligenciadas do ponto de vista do melhoramento de plantas e do desenvolvimento agrícola, uma vez que há menos dinheiro e infra-estrutura disponível para a pesquisa com essas culturas. M esmo assim, essas culturas são muito importantes para a alimentação colombiana e para os pequenos agricultores que produzem grande parte dos alimentos do país. 
Hay cosas que es mejor que compremos porque no tenemos el tiempo ni el dinero para desarrollarlas. Pero en cambio... los grandes cultivos están en manos de las trasnacionales. Es un hecho pero tenemos otros cultivos como los promisorios que las nacionales no van a tomar porque no les interesa como mercado. Eso es lo que tenemos que desarrollar nosotros. Pero tenemos que dar la información, esto solo es un sistema más que nos garantiza un producto máscontrolado desde el punto de vista genómano. Que antes de ser liberado se han evaluado todos los riesgos, y que tenemos un sistema normativo que garantiza que se ha evaluado esto, y que no va a afectar la salud ni el ambiente.

Culturas que precisam de mais desenvolvimento agrícola, mas que não interessam às multinacionais, foram mencionadas repetidas vezes. Em alguns casos, os cientistas alegaram ter escolhido as culturas com as quais trabalharam precisamente por estas razões:

Entonces a míme interesaba trabajar con la especie que fuera de interés nacional, que además estuviera siendo utilizada por todos los sectores de la producción, zonas de economía campesina hasta productores orientados a la exportación. Y que fundamentalmente me permitiera desarrollar procesos de empoderamiento del país, del conocimiento con respecto a los recursos genéticos, $y$ entonces pues además hay algo arrastrado por mis ancestros campesinos. [...]

... Si se utiliza solo para apoyar la gran producción agrícola y social, van a tener razón los compañeros de la red pan América latina libre de transgénicos en considerar que es una instrumentación de la ciencia que solo le sirve a los poderosos. 
Em alguns casos, essa preocupação em trabalhar com culturas tropicais negligenciad as ${ }^{2}$ estava associada à vontade de aproveitar ao máximo a biodiversidade da Colômbia, a fim de oferecer uma contribuição unicamente colombiana nessa área.

Colombia es un país megadiverso y si encontramosgenes de mejor adaptación frente a sequías, plagaso de mejor calidad, se pueden introducir a las especies nativas en las cuales las multinacionales no están interesadas. Si los colombianos no lo hacemos, nadie lo hará. Es el caso de los frutales tropicales.

\section{Mas será que vai funcionar? O bstáculos para o uso bem sucedido da engenharia genética na Colômbia}

A possibilidade de utilizar a biotecnologia, sobretudo a modificação genética, para melhorar a vida das pessoas nos países em desenvolvimento tem sido criticada por muitos como, por exemplo, Vandana Shiva (2000) e M iguel Altieri (Altieri \& Rosset, 1999; Altieri, 2001; Altieri \& Rosset, 2002). Altieri, em particular, sugeriu que a engenharia genética servirá apenas para aumentar a tendência ao uso de produtos químicos e monoculturas nocivas, reduzirá a biodiversidade das culturas, além de ser mais dispendiosa do que outros tipos de pesquisa agrícola e, como está voltada para o lucro, é pouco provável que chegue aos agricultores dos países mais pobres. Ele afirma que 0 investimento na pesquisa e no conhecimento de práticas de agricultura sustentável seria uma alternativa muito mais prática para o mundo em desenvolvimento.

2 Curiosamente, embora o potencial de trabalho das culturas tropicais negligenciadas para os agricultores colombianos tenha sido mencionado repetidas vezes, a possibilidade de adquirir novos direitos de propriedade intelectual como resultado de seu trabalho nunca foi diretamente referida pelos cientistas entrevistados. 
O s cientistas colombianos que foram entrevistados acreditam que a tecnologia poderia ter aplicação útil, mas reconhecem que existem muitos obstáculos para a implementação bem-sucedida dos seus projetos de engenharia genética. Eles admitem que esse tipo de pesquisa é dispendioso, 0 que torna ainda mais difícil a sua concretização. Além disso, a disputa por bolsas de pesquisa é muito acirrada. É mais difícil encontrar financiamento para projetos de médio ou longo prazo do que para projetos de dois a três anos. Isso pode dificultar a obtenção do dinheiro necessário para a boa formação dos alunos em longo prazo. Além disso, alguns pesquisadores declararam, durante a entrevista, que é importante encontrar fontes de financiamento externo porque as fontes nacionais poderiam ser incertas ou demoradas. Desta forma, praticamente todos os cientistas entrevistados afirmaram que a aquisição de recursos para a pesquisa constitui o maior obstáculo.

La biotecnología en relación con otros métodos de mejoramiento es costosa para los países en vía de desarrollo, porque el equipamiento para hacer transgénesis es costoso, los reactivos son costosos, capital humano, información, etc., son muy costosos. Pero pienso son herramientas poderosas para cambiar el futuro. Yo creo que necesitamos conocer lo que tenemos, pues tal vez no es necesario hacer mutación genética sino que la naturaleza misma ya lo ha hecho pornosotros y nosotros no lo sabemos, sobretodo en el trópico donde tenemostanta biodiversidad e interacción entre estos organismos, por lo que lo primero es conocer lo que se tiene para así saber qué y cómo utilizarlo.

Um pesquisador, enquanto descrevia como um dos seus projetos havia 'vazado' (quando uma linha de pesquisa é completada por outra equipe antes que o pesquisador original tenha terminado a sua própria pesquisa na mesma área), comentou que não é a falta de criatividade ou de conhecimento que atrapalha a ciência na América Latina, mas a falta de recursos. 
Es por esto que muchas veces se piensa que en Latinoamérica no se tienen los conocimientos suficientes para crear nuevas cosas o hacer nuevos descubrimientos. Pero lo que verdaderamente falta son recursos para poder desarrollar las investigaciones y así poder mostrar resultados al mundo entero.

U ma pesquisa bem-sucedida nessa área exige também que se considere a propriedade intelectual, o que foi mencionado como sendo outra provável dificuldade. 0 s pesquisadores empregaram duas estratégias em potencial. 0 material de pesquisa precisava ser escolhido com muito cuidado para que a propriedade intelectual envolvida fosse acessível ${ }^{3}$. Isso poderia incluir cooperação com uma instituição pública que estivesse trabalhando com o gene ou o processo em questão. Ao mesmo tempo, os pesquisadores precisavam estar preparados para negociar pelo acesso ao material, genes, ou protocolos técnicos, muitas vezes com empresas multinacionais. Dois ou três pesquisadores enfatizaram que, como pesquisadores acadêmicos, assim como seus colegas, eles precisaram informar-se mais sobre os direitos de propriedade intelectual envolvidos. Além disso, eles precisam trabalhar em conformidade com os acordos internacionais, tais como a Convenção sobre a Diversidade Biológica:

Muchos investigadores no conocen el Convenio de diversidad biológica y alguons creen que se refiere solo a la biodiversidad pero no leen el párrafo que hay sobre garantizar el acceso a los beneficios de la tecnología a la gente. Y eso es una obligación que tenemos.

3 Algumasinstituições públicase não-lucrativas estão trabalhando para tornar a informação biológica mais acessível, como é o caso da iniciativa de Richard Jefferson com a CAMBIA (Centro para a Aplicação da Biologia M olecular na Agricultura Internacional) e a Biological Innovation O pen SourceBIOS (Inovação Biológica para uma Sociedade Aberta) (CAM BIA, 2007). 
O custo dos testes para satisfazer os requisitos regulamentares, antes que um projeto bem-sucedido possa ser liberado e utilizado pelos beneficiários ao qual está destinado, é outra complicação da engenharia genética. É preciso buscar financiamento para esses testes, o que nos leva de volta à já mencionada dificuldade para conseguir financiamento.

\section{Por que fazer algo tão difícil?}

Apesar dos custos, dos desafios técnicos envolvidos na pesquisa, e dos obstáculos regulamentares e de propriedade intelectual, muitos dos pesquisadores entrevistados afirmaram que era importante tentar realizar esse trabalho utilizando essa tecnologia. Eles acreditam que os resultados da pesquisa poderiam ser suficientemente importantes para fazer valer o esforço de prosseguir.

La pregunta es que si hay una variedad transgénica con características importantes si se amerita el costo; si es imperativo hay que afrontarlo en caso de que resuelva problemas sociales y económicos.

A pesquisa agrícola do hemisfério norte não vai atender aos interesses do hemisfério sul, ou tropical. Foi dito que a agricultura colombiana existe em seu próprio contexto único e que os cientistas colombianos precisam corresponder a essas condições com a pesquisa adequada.

El tipo de ingeniería genética que se hace en los países desarrollados, obedece a unas lógicas económicas (i? A unas condiciones ecosistémicas diferentes a las nuestras. Nosotros tenemos agricultura tropical, allá tienen agricultura de zona templada, que son cosas diferentes. Nosotros tenemos una economía muy diversificada en la que participan desde comunidades indígenas, comunidades afro colombianas, en nuestro 
caso, hasta agricultores como los del Valle del Cauca que son jugadoresglobales. En ese sentido entonces, la lógica que yo defiendo es que el tipo de ciencia que hacemos sí tiene que responder a nuestro contexto. Lo que no significa que estemos haciendo ciencia tercer mundista. Sino que en general como los procesos de globalización, por lo menos yo los entiendo. Es tomar esos elementosy darlesel sentido convencional. Entonces aquí no se desarrollan procesos que les sirvan a todos los sectores de la producción. Esos tipos particularesde tecnología tienen sus limitaciones para ser apropiadas por la sociedad.

Não se fala da engenharia genética como um instrumento para ser usado em todos os casos, mas sim, como uma ferramenta que poderia ser convenientemente aplicada em determinadas condições. É necessário salientar que muitos dos cientistas entrevistad os têm experiência com o melhoramento convencional de plantas, e que alguns deles ainda realizam programas de pesquisa de melhoramento convencional simultaneamente com seus programas de pesquisa biotecnológica. Eles acreditam que a engenharia genética, como uma ferramenta, tem um propósito específico, que não é o de substituir outros métodos.

Para mí, la transformación genética es una tecnología muy puntual, no es genérica, es donde la necesitamos, y para qué la necesitamos y cuándo la necesitamos. [... ] Y lo otro que me gustaría enfatizar es que antes de comenzar un proyecto grande de transformación genética hay que explorar la variabilidad genética existente.

O período de tempo necessário para desenvolver programas de pesquisa é outro fator importante para se entender porque os pesquisadores continuaram a trabalhar com a engenharia genética (H olmes, 2006). A pesquisa exige um longo período de tempo e não se pode esperar para medir a opinião pública ou prever a regulamentação antes de começar a trabalhar 
com a tecnologia, uma vez que é necessário adquirir conhecimentos e competências na área. Q uanto custa esperar para dar início a uma área de pesquisa? Significa que os problemas continuam sem solução, ainda, ou que são resolvidos apenas quando se trata de variedades vegetais que não são importantes para os trópicos? 0 pesquisador abaixo, por exemplo, defende que a pesquisa merece uma tentativa apesar da antecipação de futuras dificuldades com testes regulamentares e outras barreiras porque a importância dessa tecnologia e os caminhos reguladores que serão adotados no futuro ainda são desconhecidos. O s resultados da pesquisa podem validar o esforço se a tecnologia ajudar a lidar com um problema grave.

En todo, si uno pensara en una planta que tuviera que pasar por todas las regulaciones, estamos hablando de muchos años de trabajo e investigación, pero tenemos que empezar de alguna forma y ese es nuestro trabajo, primero identificar qué sustancias podrían afectar la broca y qué pudiéramos poner en la planta del café, trabajar en todo los sistemas de regeneración y transformación, todo lo que eso implica, y seguir con todo el proceso $y$ si finalmente logramos tener algo que sea bueno, le vamos a decir a los caficultores "tenemos algo bueno", pero de ahí a pensar que vamos a comercializar esto pasa mucho tiempo. Sin embargo, no debemosrechazar la tecnología desde ya, puesno sabemos qué va a pasar, de pronto podemos hacer algo muy bueno para ellos, $y$ si el publico la acepta sería excelente porque realmente la broca le causa problemas gravísimos en la caficultora colombiana. Es muy, muy, muy duro

Admite-se então que a tecnologia não pode ser aplicada em todas as situações, e que diferentes métodos podem ser mais úteis em alguns casos. No entanto, há um sentimento geral de que a tecnologia detém uma promessa que eles não estão dispostos a rejeitar, não obstante as dificuldades e custos inerentes à continuação da pesquisa em engenharia genética. 
Em resumo, os cientistas entrevistados se recusam a aceitar que a tecnologia não é adequada simplesmente porque custa caro, e os recursos podem ser difíceis de obter.

\section{Discussão: Participar da pesquisa de engenharia genética por rejeição aos limites hegemônicos ou por idealismo?}

As motivações para participar da pesquisa de engenharia genética de plantas são complexas. Para ilustrar essa complexidade, serão apresentadas duas possíveis interpretações para entender o compromisso com a utilização da tecnologia de engenharia genética descrito acima. Primeiro, é dado a entender que a posição dos cientistas entrevistados para este trabalho pode ser interpretada como uma rejeição à idéia de que tecnologias dispendiosas não devem ser utilizadas em contextos de recursos limitados. Esta idéia pode ser melhor compreendida através do conceito de 'tecnologia apropriada' e sua análise. A seguir, recomenda-se uma interpretação alternativa, na qual o uso da engenharia genética é um exemplo da hipérbole tecnológica, ou esperança de salvação através do progresso científico, com o qual o desenvolvimento tem sido relacionado historicamente.

Paul Farmer (2001) sustenta que, com relação à medicina no Haiti e em outros países pobres, o conceito de 'tecnologia apropriada' é utilizado para manter privilégios e vetar o acesso à tecnologia para os contextos de recursos limitados. Tal conceito foi originalmente cunhado por E.F. Schumacher (1973) para se referir à falta de uma tecnologia 'apropriada' ou 'intermediária' para os países em desenvolvimento. Para Schumacher, uma tecnologia mais acessível, criada a partir de materiais locais e ao alcance financeiro de um número maior de indivíduos promoveria o desenvolvimento econômico. Seu argumento era o de que a tecnologia industrial, extremamente eficiente, de ponta, necessariamente não gera empregos, uma vez que essa tecnologia é quase sempre idealizada para reduzir o 
número de homens-hora. A argumentação de Schumacher só é possível em contexto econômico, e Kammen \& D ove (1997), por exemplo, continuam a apelar para o desenvolvimento de uma tecnologia mais acessível, uma prática que eles chamam de 'ciência mundana'. Contudo, o termo 'tecnologia apropriada' se espalhou rapidamente, tanto nos países desenvolvidos, em debates so bre a natureza da sociedade moderna (W inner, 1986), quanto na definição de prioridades de desenvolvimento (Farmer, 2001).

É com este último que Farmer tem ressalvas, presumindo que o conceito contraria a idéia de que cuidados de saúde são um direito para aqueles em contextos pobres. Segundo Farmer, aqueles que sofrem com a AIDS nos contextos de recursos limitados querem ter acesso aos hospitais e tratamentos, e não a programas preventivos 'custo-benefício':

Uma das primeiras coisas que devemos fazer é escutar àqueles que estão infectados pelo HIV. São quarenta milhões e aumentando, e eles não estão nos dizendo para concentrar todas asnossas atividades relacionadas à AID S na prevenção. Elesnão estão nos avisando que a terapia anti-retroviral não é custo-benefício. Eles não estão questionando se intervenções terapêuticas onerosas são ou não são 'sustentáveis' em contextospobres, se essa é ou não a 'tecnologia apropriada' para aszonas de baixa tecnologia do globo. Muitas vezes, eles estão dizendo exatamente o contrário, porque doentes miseráveis nos lembram de que os sacrossantos mecanismos de mercado não vão servir aos interesses da saúde global igualitária (Farmer, 2001: xxiii).

N este contexto, Farmer defende que o tratamento não pode ser apenas a província dos ricos, e que devemos suspeitar dos relatórios de saúde pública que afirmam que todas as intervenções médicas precisam ter 0 caráter 'custo-benefício'. “Não podemos mais aceitar o que nos dizem sobre 'recursos limitados'... A riqueza do mundo não se esgotou; apenas 
tornou-se inacessível para aqueles que mais precisam dela". (Farmer, 2001: xxvi). Para Farmer, decidir se alguma coisa é ou não uma 'tecnologia apropriada' equivale a dizer que alguns seres humanos têm direito a um nível de tecnologia diferente dos outros.

A vontade dos pesquisadores ao agirem ante as dificuldadese utilizarem uma tecnologia que eles acreditam que será vantajosa para a agricultura da Colômbia, poderia ser interpretada como um ato de rebeldia contra os que pensam que a engenharia genética não é adequada para aqueles que vivem em um contexto de recursos limitados. Restringir a engenharia genética aos países mais ricos implica uma hegemonia científica ${ }^{4}$ na área que parece não ser aceita pelos cientistas colombianos que fazem uso da tecnologia. A posição doscientistas demonstra sua vontade de proporcionar uma maior distribuição dos benefícios que resultam dessa tecnologia. Além disso, desafia a concentração da tecnologia nas mãos de corporações multinacionais do hemisfério norte. Resta então saber se o direito à saúde e o direito à pesquisa agrícola são equivalentes.

U ma interpretação alternativa da posição dos cientistas colombianos que trabalham com engenharia genética seria inserir suas declarações na história do discurso do desenvolvimento através do progresso científico. Arturo Escobar (1995) acredita que o aumento do discurso do desenvolvimento, como uma política proeminente no período pós-Segunda Guerra $M$ undial, na realidade contribuiu para o maciço subdesenvolvimento, empobrecimento e exploração, e não, para o bem-estar social e econômico de muitos países que foram beneficiários de iniciativas de desenvolvimento, inclusive a Colômbia. U ma forte crença nos poderes da ciência e da tecnologia para promover o 'progresso' social foi peça fundamental das políticas voltadas para o desenvolvimento. Acreditava-se que o progresso científico, como

4 Esse termo está sendo usado como referência ao predomínio na área, sem relação com o conceito mais específico de hegemonia cultural desenvolvido por Antonio Gramsci. 
uma forma de determinismo tecnológico, conduzisse ao crescimento econômico e à melhoria social. 0 apelo da tecnologia continuou a ser associado a iniciativas mais recentes de desenvolvimento neoclássico (Yapa, 1996). A obra de Escobar adverte contra a aceitação sem restrições da promessa da tecnologia de resolver problemas sociais e econômicos.

Surge uma poderosa combinação quando a idéia de contribuir para o desenvolvimento através do progresso científico é associada ao desejo profissional de participar da vanguarda da ciência agrícola; incluindo tudo o que isto implica, em termos de aumento de publicações e bolsas de pesquisa. Neste sentido, o idealismo parece vencer o senso comum se for levado em consideração o fato de que os recursos seriam mais efetivos, se utilizados para fortalecer os esforços de pesquisa com a ciência convencional de melhoramento de plantas e culturas. Dentro desta interpretação, deixar o melhoramento convencional de plantas por áreas mais populares da biotecnologia poderia ser visto como parte da 'febre' da biologia molecular. Como constatou Escobar (1995), no contexto de uma pesquisa de outro tipo, a pesquisa em engenharia genética de plantas na Colômbia pode contribuir para a produção de conhecimento que está com concentrado em outros lugares, à custa das necessidades e interesses agrícolas da Colômbia.

A 'árvore de pesquisa' foi transplantada do norte para o sul, e assim a América Latina tornou-se parte de um sistema transnacional de pesquisa. Embora essa transformação tenha criado novas capacidades de conhecimento, como defendem alguns, também acarretou uma maior perda de autonomia e o bloqueio de diferentes formas de conhecimento (Escobar, 1995: 37).

Foram apresentadas duas interpretações com o objetivo de mostrar que talvez sejam inevitáveis as múltiplas interpretações de decisões como, por exemplo, a direção da pesquisa científica, principalmente nos casos que envolvem mudança tecnológica, já que há muito em jogo nessas deci- 
sões. Como destaca Sandra H arding, a mudança tecnológica traz consigo questões importantes sobre a distribuição de recursos, poder e status. “M omentos de mudança científica e tecnológica são sempre espaços de disputa sobre a forma como os benefícios e custos da mudança serão distribuídos" (Harding, 1998: 5). Voltando às justificativas para a engenharia genética e a sua utilidade no mundo em desenvolvimento: as barreiras à sua utilização, no caso da Colômbia, mostram o quanto é improvável que a engenharia genética venha a oferecer uma contribuição global em larga escala para os problemas da fome enquanto a sua utilização estiver voltada principalmente para o lucro. É um caso em que, como sugeriu Burkhardt (2001), benefícios futuros ou contribuições para o ‘bem público' a partir de uma tecnologia não podem ser presumidos, mas sim, demonstrados. Em certa medida, ainda não se sabe se a engenharia genética será útil para os cientistas e agricultores colombianos. Mesmo assim, os cientistas entrevistados para este trabalho estão ativamente engajados na luta para mudar a forma como os benefícios dessa tecnologia poderiam ser distribuídos com mais igualdade.

\section{Referências}

ALTIERI, M . A. Genetic engineering in agriculture: the myths, environmental risks, and alternatives. Oakland, CA: Food First/Institute for Food and Development Policy, 2001

ALTIERI, M. A. \& RO SSET, P. Diez razones que explican por qué la biotecnología no garantizará la seguridad alimentaría, ni protegerá el ambiente, ni reducirá la pobreza en el tercer mundo. Food First/Institute for Food and D evelopment Policy, 1999. [O n-line]. Available: http://www.foodfirst.org/progs/global/ge/altieri-1199s.html

ALTIERI, M. A. \& RO SSET, P. Ten reasons why biotechnology will not ensure food security, protect the environment, or reduce poverty in the developing world. In R.Sherlock \& J. D. Morrey (Eds.), Ethical issues in biotechnology (pp. 175-182). Lanham, Boulder, N ew York, Oxford: Rowman \& Little Publishers, Inc, 2002. 
BORLAUG, N. E. Ending world hunger: the promise of biotechnology and the threat of antiscience zealotry. In F.H .Buttel \& R. M. Goodman (Eds.), O f frankenfoods and golden rice: risks, rewards, and realities of genetically modified foods (pp. 2534). Madison: W isconsin Academy of Sciences, Arts and Letters, 2001.

BRO O KES, G. \& BARFO OT, P. Brief 36: GM Crops: The First Ten Years - Global Socio-Economic and Environmental Impacts Ithaca, NY: ISAAA, 2006.

BU RKH ARDT, J. Agricultural biotechnology and the future benefits argument. Journal of Agricultural and Environmental Ethics, 2001. 14 , p. 135-145.

CAMBIA. CAM BIA Homepage. http://www.cambia.org/daisy/cambia/home.html [O n-line]. Available: http://www.cambia.org/daisy/cambia/home.html, 2007.

D RU CKER, P. F. Post Capitalist Society. N ew York: HarperBusiness, 2003.

ESCOBAR, A. Encountering Development: The Making and Unmaking of the Third World. Princeton: Princeton University Press, 1995.

FALCON, W. P. \& FOW LER, C. Carving U p the Commons - Emergence of a $\mathrm{N}$ ew International Regime for Germplasm Development and Transfer. Food Policy, 2002. 27, 197-222.

FARM ER, P. Infections and Inequalities: The Modern Plagues. (Paperback ed.) Berkeley, Los Angeles, London: U niversity of California Press, 2001.

HARDING, S. Is Science Multi-Cultural? Postcolonialisms, Feminisms, and Epistemologies. Bloomington and Indianapolis: Indiana University Press, 1998.

HAYDEN, C. When Nature Goes Public: The Making and Unmaking of Bioprospecting in M exico. Princeton, New Jersey: Princeton Unviersity Press, 2003.

HERRERA-ESTRELLA, L. R. Genetically M odified Crops and Developing Countries. Plant Physiology, 2000. 124, 923-925.

HOLMES, C. GMOs in the Lab: O bjects without Everyday Controversy. Focaal: european journal of anthropology, 2006, 35-48

KAM M EN, D. M. \& DO VE, M. R. The Virtues of Mundane Science. Environment, 1997, 39, 10-15-38-41.

LURQ U IN , P. F. The Green Phoenix: A History of Genetically M odified Plants. N ew York: Columbia University Press, 2001. 
MARTIN, P. Winning the World Over: Speech by the Honourable Paul Martin, Minister of Finance for Canada, to the Canadian Society of New York. http:// www.fin.gc.ca/news01/01-007e.html [O n-line]. Available: http://www.fin.gc.ca/ news01/01-007e.html, 2001.

MCGLOUGHLIN, M. Ten reasons why biotechnology will be important in the developing world. In R.Sherlock \& J. D. Morrey (Eds.), Ethical issues in biotechnology (pp. 161-173). Lanham, Boulder, N ew York, Oxford: Rowman \& Little Publishers, Inc. 2002.

PARAYIL, G. Mapping Technological Trajectories of the Green Revolution and the Gene Revolution from Modernization to Globalization. Research Policy, 2003, 32, 971-990.

SCHU M ACHER, E. F. Small is Beautiful: Economics as if People Mattered. London: Blond and Briggs, 1973.

SHIVA, V. Stolen Harvest. Cambridge, M A: South End Press, 2000.

TAM BO RNINI, E. Biotecnología: La O tra Guerra. (1st Edition ed.) Buenos Aires, Argentina: Fondo de Cultura Económica, 2003.

WINNER, L. The whale and the reactor: a search for limits in an age of high technology. Chicago: University of Chicago Press, 1986.

YAM IN, F. Intellectual Property Rights, Biotechnology and Food Security (Rep. No. IDS Working Paper 203). Brighton, Sussex: Institute of Development Studies, 2003.

YAPA, L. Improved Seeds and Constructed Scarcity. In R.Peet \& M. Watts (Eds.), Liberation Ecologies: Environment, Development, and Social Movements (pp. 69-85). New York: Routledge, 1996. 


\section{Resumo:}

A biotecnologia e a engenharia genética de plantas têm forte apelo na Colômbia, devido ao potencial que essa tecnologia proporciona para participar da nova economia do conhecimento e também como uma forma de explorar a grande biodiversidade do país. Contudo, a tecnologia de engenharia genética e a produção de conhecimento resultante são dominadas por interesses e recursos do hemisfério norte. Cientistas colombianos que fazem uso da engenharia genética devem trabalhar dentro desse contexto. Ainda assim, muitos acreditam que seus projetos de pesquisa beneficiarão a Colômbia. Essa tecnologia, portanto, oscila entre o otimismo quanto ao seu futuro em potencial e as barreiras impostas pelas condições globais em que ocorre.

Palavras-chave: Engenharia genética, biotecnologia e tecnologia

Recebido: 06/12/2007

Aceite final: 07/01/2008 


\section{The Lure of Plant Genetic Engineering for Colombian Scientists}

\section{Christina Holmes}

Biotechnology and plant genetic engineering hold strong appeal in Colombia, due to the technology's potential to enable participation in the new knowledge economy and as a way of harnessing the country's great biodiversity. However, genetic engineering technology and its related knowledge production are dominated by northern interests and resources. Colombian scientists employing genetic engineering must work within this context. Nonetheless, many to hope that their research projects will benefit Colombia. This technology is therefore negotiated between optimism for future potential and the constraints of the global conditions in which it takes place.

Keywords: Biotechnology, genetic engineering and technology 